\section{Gedanken zu einer Ausstellung}

F. Gafner

Warum stellt ein Arzt im Ruhestand mit bloss autodidaktisch erworbenen Fertigkeiten seine Bilder aus? In der Nordwestecke der Schweiz allein finden sich etwa achthundert, grösstenteils professionelle Künstler, welche auf den Verkauf ihrer Werke angewiesen sind. Ein Sachverhalt, der wohl bis anhin für die Ärzteschaft noch nicht gilt. Warum also ausgerechnet ein Arzt?

$\mathrm{Zu}$ dieser Frage möchte ich einige Überlegungen machen. Die Anforderungen an den Mediziner in der Praxis sind anerkanntermassen hoch. Neben ausgewiesenem Wissen und Können sind doch auch Verantwortungsbewusstsein, Einfühlungsvermögen in die oft psychosomatischen Probleme des Patienten und damit eine Fähigkeit zu spontaner Intuition, also kreatives Denken gefragt. Und sollte der Arzt so gesehen nicht auch ein wenig Künstler sein?

Auffällig viele Mediziner/innen sind kreativ tätig (nicht zuletzt bekannt gemacht in der Schweizerischen Ärztezeitung). Sei es als Wissenschaftler mit der oft plötzlich erlösenden genialen Eingebung, sei es als Dichter oder Schriftsteller, Komponist oder $\mathrm{Mu}$ siker, oder was auch immer.

Künstlerische Schöpferkraft scheint dem Menschen seit Urzeiten angeboren zu sein. Erinnern wir uns an die franko-kantabrische Höhlenkunst aus der Zeit der letzten grossen Vereisung, die etwa 10000 v. Chr. zu Ende ging. Die eidetischen Strichzeichnungen zeigen längst ausgestorbene Tierarten mit geradezu beschwörender Intensität. Kreativität ist der Motor der Menschheitsentwicklung. Sie ist so ausgeprägt, dass der Kunstschaffende einen zwingenden Drang zur Verwirklichung seiner Ideen hat. Er will und kann nicht einsamer Rufer in der Wüste bleiben. Er muss eine Resonanz im Publikum verspüren, und so geht er gelegentlich mit seinem Werk vor die Öffentlichkeit. Warum also nicht auch ein Arzt?

Wissenschaftlich ist das Wesen der Kunst sehr oft definiert worden. Es bleibt aber schier unmöglich, Kunst umfassend zu beschreiben, es fehlen im üblichen Sprachgebrauch die präzisen Worte, siehe Dadaismus. Kunst kann nur gefühlsmässig gültig erfasst werden. Albert Einstein hat sich dazu trefflich geäussert: «Das Schönste, das wir erfahren dürfen, ist das Geheimnisvolle. Es ist die Wurzel aller Kunst und Wissenschaft."

Korrespondenz: Frank Gafner Rebgasse 15 CH-4410 Liestal

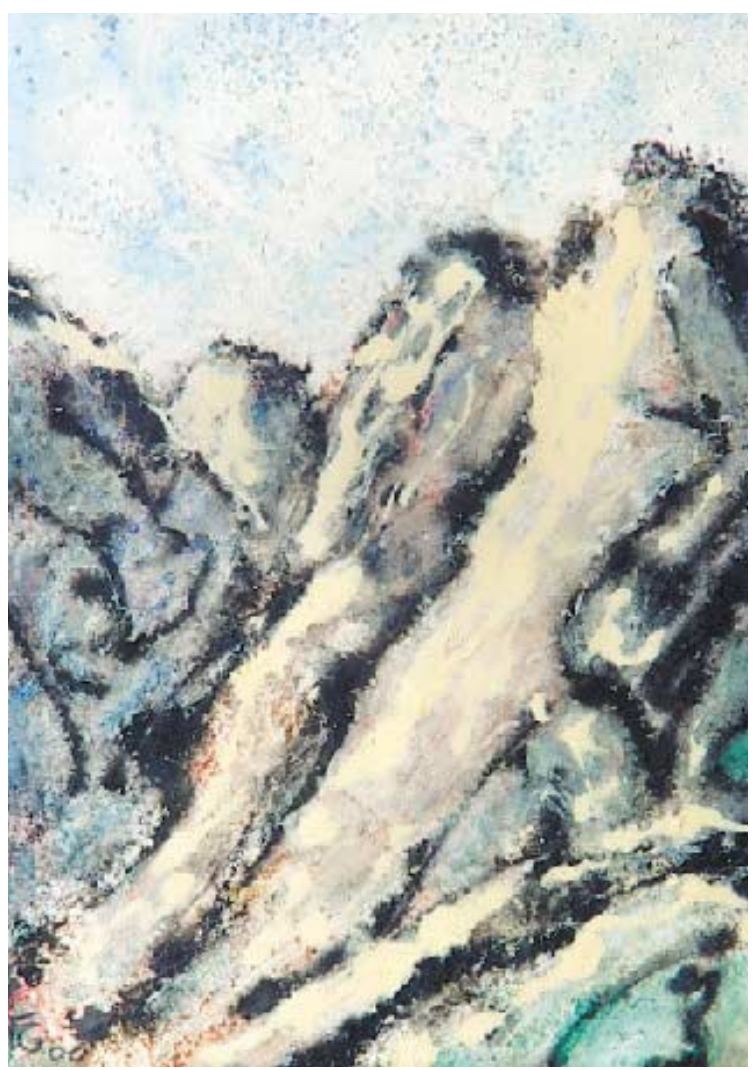

Runsen

Natürlich geziemt es sich nicht, eigene Werke wertend zu beschreiben. Dafür sind die Kritiker zuständig. Deshalb möchte ich nur berichten, warum mein Interesse neben abstrakter Ausdrucksweise besonders der Darstellung von Bergen, Bäumen und Gesichtern gilt.

Gebirge als Wahrzeichen unserer Heimat haben eine sehr majestätische Ausstrahlung, welche der Berner Gelehrte und Arzt Albrecht von Haller 1729 wohl erstmals in seinem episch-philosophischen Lehrgedicht "Die Alpen» feierte. Etwa hundert Jahre später malte William Turner auf einer Studienreise durch den Alpengürtel ins Visionäre gesteigerte Aquarelle voller Licht und Atmosphäre. Ihm folgten dann die englischen Bergtouristen mit Begeisterung, was ja in alten kolorierten Stichen häufig dargestellt ist. Heute werden an Kunstauktionen Werke aus der Bergwelt von Augusto Giacometti und Ludwig Kirchner sowie vielen anderen Künstlern zu absoluten Rekordpreisen ersteigert. Dass die Berggeister aber auch Schutt und Schlammlawinen über Steilhänge und durch tiefe Felsrunsen hinunter auszulösen imstande sind, ist uns allen in erschreckendem Ausmass kürzlich wieder schmerzlich zur Kenntnis gebracht worden.

Die Metapher Baum ist ein Grundmuster unseres Lebens mit dem Verwurzeltsein, dem Emporwachsen und Entfalten seines Ast- und Laubwerkes, sein Spätherbst mit dem melancholischen gelblich-braunen Blätterfall Symbol der Vergänglichkeit. Die alten Götter des nahen Ostens und der germanischen Helden- 


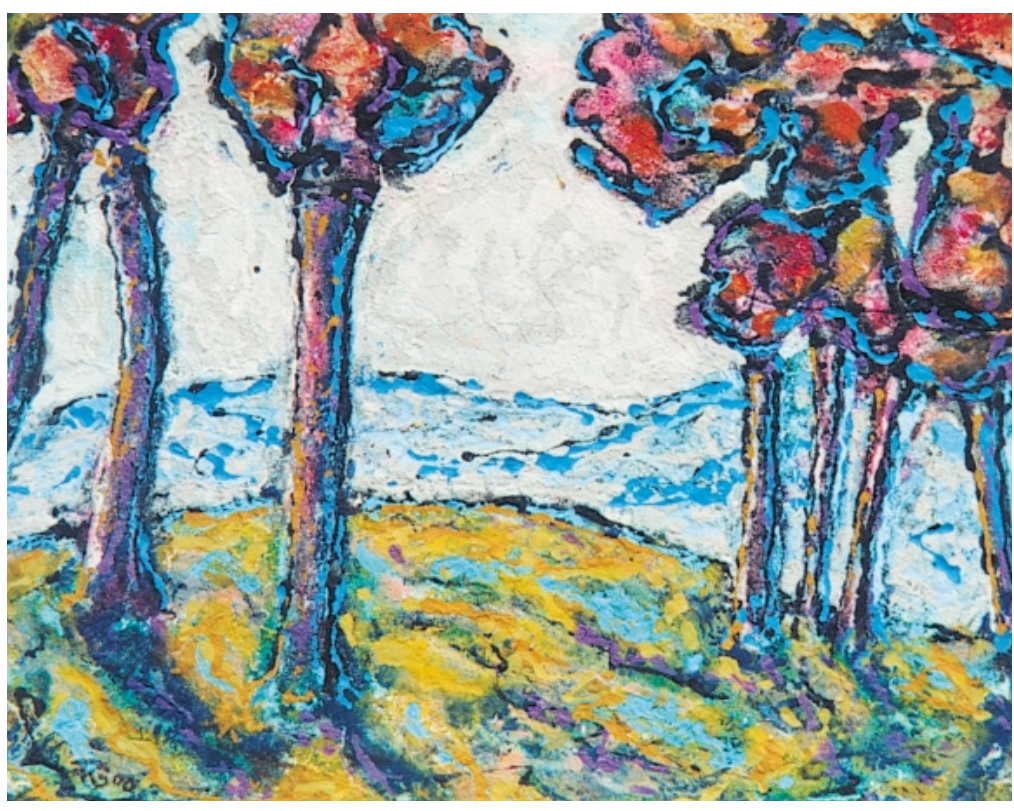

Herbst im Massif central

sagen wurden häufig unter Bäumen geboren. In den Veden ist der Baum geheiligt. Und noch heute werden in Nepal gewisse Bäume als Sinnbild von allerlei Göttern und launischen Geistern betend verehrt. In allen Weltreligionen wird der «arbor vitae» besungen. Und der grosse Reformator Martin Luther verlieh seiner Lebensauffassung tiefsten Sinn mit dem wundervollen Ausspruch: «Und wenn ich wüsste, dass morgen die Welt unterginge, würde ich heute ein Apfelbäumchen pflanzen."

$\mathrm{Zu}$ den Gesichtern, im besonderen zu den Bildnissen von Frauenphysiognomien, will ich mich kurz fassen, obschon dieses Thema sehr faszinierend ist. Jedermann (jeder Mann) wird verstehen, was ich damit meine. Archetypisch sind uns die Frauen als Traumbilder stets vor Augen. Als umworbene Geliebte, als kameradschaftlich mitfühlende Lebenspartnerin und als fürsorgliche Mutter unserer Kinder. Vielleicht für einige Feministinnen etwas sehr veral- tet formuliert. Aber es ist nun einmal so: Die Frau ist das Gefäss unseres Daseins im wörtlichen wie im übertragenen Sinn!

Ein französischer Künstler, dessen Name mir leider nicht mehr gegenwärtig ist, äusserte sich in typisch pariserischem Jargon kurzbündig, aber doch irgendwie sehr ehrlich folgendermassen dazu: «La femme est la création la plus éclatante du Bon Dieu, je le remercie tous les jours." Was meinen die Feministinnen dazu?

Es ist noch nachzutragen, dass der Reingewinn der Verkaufsausstellung den «Médecins sans frontières» in Genf zugute kommt, leider ohne berauschendes Ergebnis.

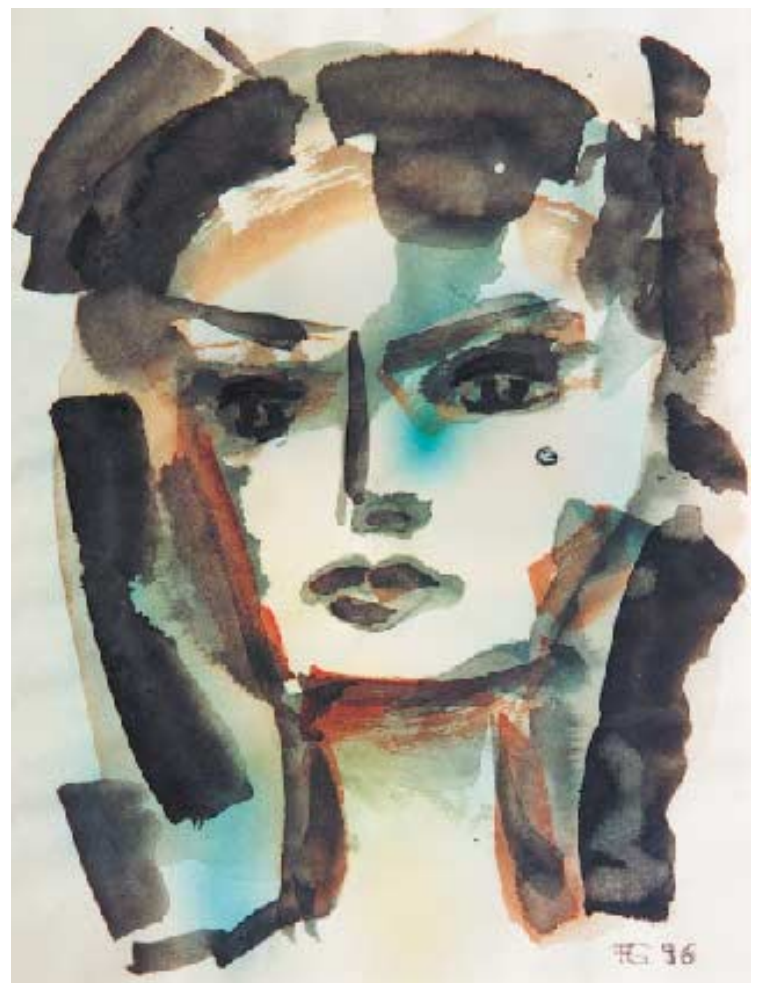

Diva 